\title{
Un estudio de las políticas sociales sobre PVVS (personas viviendo con VIH-Sida) en la ciudad de Río Gallegos Provincia de Santa Cruz (2015 - 2017)
}

\section{A study of social policies on PLWHA (people living with HIV / AIDS) in the city of Río Gallegos Province of Santa Cruz (2015 - 2017)}

Sergio Daniel Ramírez, Raquel Escobar, Herna Bustamante, Iris Pérez, Javier Mocca, Edurne Zubimendi, Alicia Guaquel, Maira Martínez, Cristina Delgado

sramirez@uarg.unpa.edu.ar,raquel.escobar@gmail.com,herny-america@hotmail.com,

Irisitap87@hotmail.com,jmocca@gmail.com,edurnezubimendi@gmail.com, aliciaguaquel@yahoo.com.ar,Maai-m_1@hotmail.com,delgadocristina@live.com Unidad Académica Río Gallegos - Universidad Nacional de la Patagonia Austral-

Departamento de Ciencias Sociales

Piloto Lero Riera y Santiago del Estero

Recibido: 28/06/2019. Aceptado: 28/10/2019

\section{RESUMEN}

El estado argentino, garantiza desde la Ley Nacional de Sida 23.798, su decreto reglamentario 1244/91 y mediante el Programa Nacional de Lucha contra los Retrovirus Humanos SIDA (LUSIDA) el suministro gratuito de la medicación antiretroviral (ARV) y el tratamiento integral para las personas viviendo con VIH SIDA (PVVS). En este contexto interesa analizar su implementación en relación a las personas conviviendo con VIH-SIDA y el modo en el cual se aborda esta problemáticas en la ciudad de Río Gallegos y describir la relación de las políticas públicas sociales en los distintos niveles municipal, provincial y ONG vinculadas a la atención, tratamiento y prevención.

Para esto se lleva a cabo una investigación de estudio descriptivo mediante la utilización de encuestas y entrevistas a las personas responsables de su implementación y entrevistas a personas conviviendo con el virus, consultas de documentos, investigaciones sobre el tema, datos estadísticos y encuestas a ONGs de la localidad. De esta indagación surge que el programa se implementa según las condiciones de atención médica y suministro de medicamentos. Aún resta que la difusión del tema para el cuidado sea una prioridad hacia la comunidad en general y para sectores de las organizaciones de la sociedad. Este escrito da cuenta de este proceso con los resultados alcanzados y los obstáculos que se presentan para cumplir con los objetivos propuestos.

Palabras clave: Políticas Públicas Sociales; Ley Nacional de Sida; Aplicación de la Ley; Sistema de Salud Provincial; Personas conviviendo con el virus.

\begin{abstract}
The Argentinian State guarantees the free provide of de antiretrorival medication (ARV) and integral treatment to people living with HIV-AIDS (PVVS) through National Law $\mathrm{N}^{\circ} 23.798$, regulatory decree $\mathrm{N}^{\circ} 1244 / 91$ and the National Program for fighting the human retrovirus AIDS (LUSIDA). It is interest of this paper to analyze the implementation, of the program regarding to people living with HIV-AIDS and the way this problem is approached in Río
\end{abstract}


Gallegos city, as also matters to describe the relationship within the social public policies through the different level of government, local, provincial and no governmental organizations (ONG) respect to treatment, prevention and attention of people living with HIV AIDS.

The above mentioned is the reason that motivated us to do a descriptive research study, using surveys and interviews to responsible persons that are in charge of the program implementation and also to people living with HIV AIDS, documentary consults, statistical data, scientific researchs about the issue and surveys to local ONGs, As a result of this research work it can be inferred that actually the program is implemented regarding medical attention conditions and medicine supplies. It remains to be worked concerning diffusion about the issue in order to attend health caring as a priority towards the general community and to large sectors of social organizations. This paper acknowledges of the process made by the research group with the achieved results and the obstacles that has arisen during the implementation of the project in order to accomplish the chosen objectives.

Key words: Social Public Policies AIDS National Law; Law enforcement; Provincial Health System; People living with HIV.

\section{INTRODUCCIÓN}

El trabajo de investigación ${ }^{1}$ responde a la convocatoria del Programa de Políticas Públicas Sociales de la Universidad Nacional de la Patagonia Austral, y se centra en conocer la aplicación del Programa Nacional de Sida en la ciudad de Río Gallegos.

El problema de salud del VIH-sida es reconocido por medio de la Ley $\mathrm{N}^{\circ} 23798$ para la atención a las personas que conviven con el virus de modo gratuito. Las acciones reconocidas en esta son desde lo médico asistencial, detección, controles clínicos y entrega de medicamentos y normas relacionadas con lo social, cultural, para la trasmisión y conocimiento del virus y cuidados necesarios para la prevención.

El trabajo de investigación se enfoca en el modo y relación existente entre los niveles nacional, provincial y municipal en la atención, tratamiento y prevención para posteriormente analizar si esta implementación responde a las necesidades que presentan las personas que conviven con el virus y si estas necesidades son cubiertas desde el programa y/o por otros espacios sociales como las Organizaciones no gubernamentales (ONG).

Por los propósitos perseguidos, el estudio es de tipo descriptivo porque interesa reunir información que tienda a aportar conocimiento actualizado para futuras indagaciones y aportar conocimiento para los distintos actores sociales y/o políticos de la provincia. Se parte de un recorte temporal que permita el acceso y análisis de la información, años 2015 a 2017 y porque en el país se produce un cambio de gobierno nacional. Desde este corte se centra en aquellos pacientes que son atendidos en el programa que no cuentan con obra social. Y en las organizaciones no gubernamentales que se encuentran en la ciudad con el objeto de indagar si realizan o no acciones relacionadas con el tema en estudio y su posible relación entre estas y los organismos de salud y las personas que conviven con el virus.

\footnotetext{
${ }^{1}$ PI 29/A418, denominado "Un estudio de las políticas sociales sobre PVVS (personas viviendo con VIH-Sida) en la ciudad de Río Gallegos Provincia de Santa Cruz (2015 - 2017)”. Director: Sergio Daniel Ramírez e integrado por: Herna Bustamante, Iris Pérez, Edurne Zubimendi, Raquel Escobar, Javier Mocca, Alicia Guaquel, y alumnas Maira Martínez y Cristina Viviana Delgado.
} 
Los antecedentes de estudios respecto a la enfermedad, que es considerada una epidemia, son profusos. Es abordado por las autoridades sanitarias, políticas e investigadores y desde Asociaciones civiles. Desde las autoridades por medio de las Políticas que emanan de Acuerdos Internacionales entre los países, como la Declaración Políticas de las Naciones Unidas de 2016, que propone las metas $2020^{2}$; los estudios estadísticos a nivel nacional que produce el Ministerio de Salud y Desarrollo Social de la Nación a través de la Dirección de Sida, ETS, hepatitis y TBC, Boletines sobre VIH, Sida e ETS en Argentina que se editan al menos una vez al año.

Respecto a las asociaciones civiles se encuentran publicaciones de la Fundación Huésped, entre otros. En cuanto a las investigaciones se centran en el estudio de las representaciones sociales sobre el virus y el Sida y sobre estudios estadísticos. Algunos de estos conocimientos producidos sobre representaciones sociales exponen que es una enfermedad que se asocia con la muerte, con las formas de vivir la sexualidad; todos son contenidos que delinean el campo representacional del VIH/SIDA, encontrándose asociaciones frecuentes en palabras como: enfermedad, muerte, miedo, homosexualidad, contaminación, contagio, infidelidad, promiscuidad, prostitución, drogas, irresponsabilidad, sexo casual. Estas llevarían a que las personas que conviven con el virus estén expuestas a la discriminación y exclusión, tanto a nivel social como en laboral (Boletín sobre el VIH, Sida e ITS en Argentina, Pecheny, 2008, Margulies, 2014, Paiva, 2018, entre otras).

El producto de esta indagación muestra que la aplicación de lo que norma la Ley está organizada en la atención hacia la persona que convive con el virus: detección, notificación, controles médicos y entrega de medicamentos. Pero no se encuentran datos que den cuenta de un abordaje como un problema social en la difusión y conocimiento del tema por parte de autoridades sanitarias, ni de las organizaciones sociales indagadas.

El escrito se encuentra organizado en una un marco general que contiene los fundamentos teóricos y legales respecto al tema, seguido de la explicación de los instrumentos en la búsqueda de información para finalizar con el análisis, conclusión y recomendaciones de todo el trabajo investigativo.

\section{ESTRUCTURA DEL DOCUMENTO}

\section{Marco de referencia}

\section{Marco histórico}

Nuestro país es uno de los primeros en la región Latinoamericana en contar con una Ley, bajo la responsabilidad del Estado, cuyo objeto es la atención y el control de la epidemia del VIHSida. Este instrumento legal garantiza la atención integral y resguarda la confidencialidad de las personas que conviven con el virus que se encuentran en tratamiento. La fecha de promulgación es el año 1.990 bajo Ley No 23.798 y su reglamento en 1991 bajo el $\mathrm{N}^{\circ} 1422$.

Su promulgación ocurre en una década en que se inicia el conocimiento del virus en sangre y su la forma de contagio. En nuestro territorio nacional el primer caso de persona que contrajo sida data del año 1.982. Luego y en el año 1.987 sucede lo mismo en el caso de una mujer. Se recuerda que al inicio de la enfermedad se piensa que afecta al grupo de hombres que eligen tener sexo con otros hombres, de aquí la importancia de este último dato.

\footnotetext{
${ }^{2}$ Estas metas se refieren a eliminar las barreras normativas que dificultan el acceso a los servicios de prevención y las desigualdades de género; poner fin a todas las formas de discriminación y hacia las personas que conviven con el VIH y las poblaciones claves.
} 
Tras la aparición de la Ley se norma la notificación de los casos a las autoridades nacionales, de personas que se infectan con el virus y las muertes ocurridas por causa de la enfermedad. Estas notificaciones son importantes porque aportan información para conocer la evolución de la infección y la enfermedad a nivel del territorio nacional y por provincia. Su importancia radica en que estos datos, son necesarios para evaluar las políticas públicas y sociales en el abordaje de esta nueva problemática social. De este modo se puede contar con estadística nacional.

Hasta la aparición de los tratamientos antirretrovirales de alta eficacia, el sida fue una enfermedad con muy alta letalidad. En los años siguientes comienza un descenso sostenido de notificación de nuevas muertes, lo cual coincide con la aplicación de las terapias antirretrovirales de alta eficacia a partir de 1.997 y con la atención y acceso de las personas infectadas por VIH a los estudios para diagnóstico y seguimiento (CD4; carga viral y test de resistencia). También el acceso a la medicación para las enfermedades oportunistas de manera universal que el Estado se ve obligado a brindar.

En nuestra provincia se inicia la atención en el año 1994 con la creación de un Comité Provincial de Sida, conformado por profesionales Infectólogo y bioquímico, a fin de dar cumplimiento con lo que prevé la Ley. En ese momento Santa Cruz ocupa el 6to lugar de personas con el virus y sida. Esta conformación en la atención va sufriendo modificaciones conforme avanza los años, los tipos de tratamiento y los cambios que se producen a nivel administrativo de la salud. Así de comité y en el año 2005 se constituye con un equipo interdisciplinario y tras la creación del Ministerio de Salud de la Provincia en el año 2011 se constituye un nuevo equipo de salud conformado por médicos Infectólogo/a, Psicólogos/as y Enfermeras/os.

Teniendo en cuenta los objetivos del presente trabajo, resulta necesario brindar un panorama acerca de la evolución del VIH y de sida en la provincia de Santa Cruz. La información considerada para este fin es la más reciente que ha difundido la Secretaría de Salud de Nación en el "Boletín sobre el VIH, sida e ITS en la Argentina", N³5, Año XXI, diciembre de $2018^{3}$.

A partir de esta información se han elaborado algunos cuadros y gráficos que brindan un panorama de la situación pasada y actual de estas enfermedades en Santa Cruz y que son analizados a continuación.

En primer lugar es importante conocer la cantidad y las fluctuaciones en la cantidad anual de casos registrados de VIH en la provincia. El Cuadro 1 muestra que la evolución de casos entre los años 2007 y 2016 muestra una tendencia creciente, a pesar de las fluctuaciones anuales.

\section{Cuadro 1. Nuevos casos de VIH en Santa Cruz. Años 2007-2016}

\begin{tabular}{lcccccccccc}
\hline Jurisdicción & $\mathbf{2 0 0 7}$ & $\mathbf{2 0 0 8}$ & $\mathbf{2 0 0 9}$ & $\mathbf{2 0 1 0}$ & $\mathbf{2 0 1 1}$ & $\mathbf{2 0 1 2}$ & $\mathbf{2 0 1 3}$ & $\mathbf{2 0 1 4}$ & $\mathbf{2 0 1 5}$ & $\mathbf{2 0 1 6}^{*}$ \\
\hline Santa Cruz & 42 & 27 & 47 & 62 & 58 & 61 & 44 & 67 & 65 & 61 \\
\hline
\end{tabular}

*Años no cerrados por retraso en la notificación.

Fuente: Total de casos notificados a la DSETHyT (Dirección de Sida, ETS, Hepatitis y TBC). Secretaria de Gobierno de Salud de la Nación. Argentina, 2018.

\footnotetext{
${ }^{3}$ Como los datos que informa la provincia se encuentran contemplados en la estadística nacional, se decide analizar considerar esta fuente de información ya que permite comparar la situación de la provincia con la región y el país
} 
Estas variaciones en un universo de por sí reducido, deben analizarse con información que pueda explicar dicho comportamiento, pero ese análisis no corresponde a los objetivos de esta investigación.

Para medir de forma adecuada la incidencia de los nuevos casos anuales y poder comparar esa evolución de la provincia con respecto al total del país y la región Patagonia, se deben considerar las tasas de VIH por 100.000 habitantes. Este indicador permite medir la magnitud de esta enfermedad en una población dada y evita realizar comparaciones incorrectas al analizar jurisdicciones con tamaños poblacionales muy diferentes.

Se puede advertir que las tasas de la región Patagonia y Santa Cruz superan a la del total país en la mayor parte del período bajo estudio, y esas diferencias llegan a ser de casi 7 puntos por encima del promedio país.

El análisis del Cuadro 2 muestra con claridad la tendencia decreciente de las tasas de VIH a nivel país. Si bien en los primeros años se registra un leve aumento, a partir de 2011 la tendencia a la baja es evidente.

Esa evolución no se observa en la región Patagonia y tampoco en Santa Cruz. En ambas jurisdicciones (región y provincia) se observan comportamientos más irregulares y una tendencia menos definida que para toda la Argentina.

Cuadro 2. Tasas de VIH por 100.000 habitantes por jurisdicción Años 2007-2016

\begin{tabular}{|c|c|c|c|c|c|}
\hline Jurisdicción & 2007 & 2008 & 2009 & 2010 & 2011 \\
\hline Total país & 14,8 & 16,7 & 16,7 & 17,3 & 17,0 \\
\hline Región Patagonia & 15,2 & 17,2 & 14,4 & 17,3 & 20,2 \\
\hline Santa Cruz & 18,9 & 12,0 & 20,4 & 22,5 & 20,4 \\
\hline Jurisdicción & 2012 & 2013 & 2014 & $2015 *$ & 2016* \\
\hline Total país & 16,6 & 16,3 & 14,2 & 13,9 & 12,0 \\
\hline Región Patagonia & 17,9 & 19,0 & 17,7 & 18,6 & 19,3 \\
\hline Santa Cruz & 20,8 & 14,5 & 21,5 & 20,3 & 18,5 \\
\hline
\end{tabular}

*Años no cerrados por retraso en la notificación.

Fuente: Total de casos notificados a la DSETHyT (Dirección de Sida, ETS, Hepatitis y TBC). Secretaria de Gobierno de Salud de la Nación. Argentina, 2018.

Este comportamiento no se observa en la Patagonia ni en la provincia. El Gráfico 1 ayuda en este análisis y allí se observa lo antes dicho; además de procesos más irregulares (en parte debido a menor cantidad de casos) la tendencia es de aumento en las tasas anuales en ambas jurisdicciones. 


\section{Gráfico 1. Tasas de VIH por 100.000 habitantes según jurisdicción}

Años 2007-2016

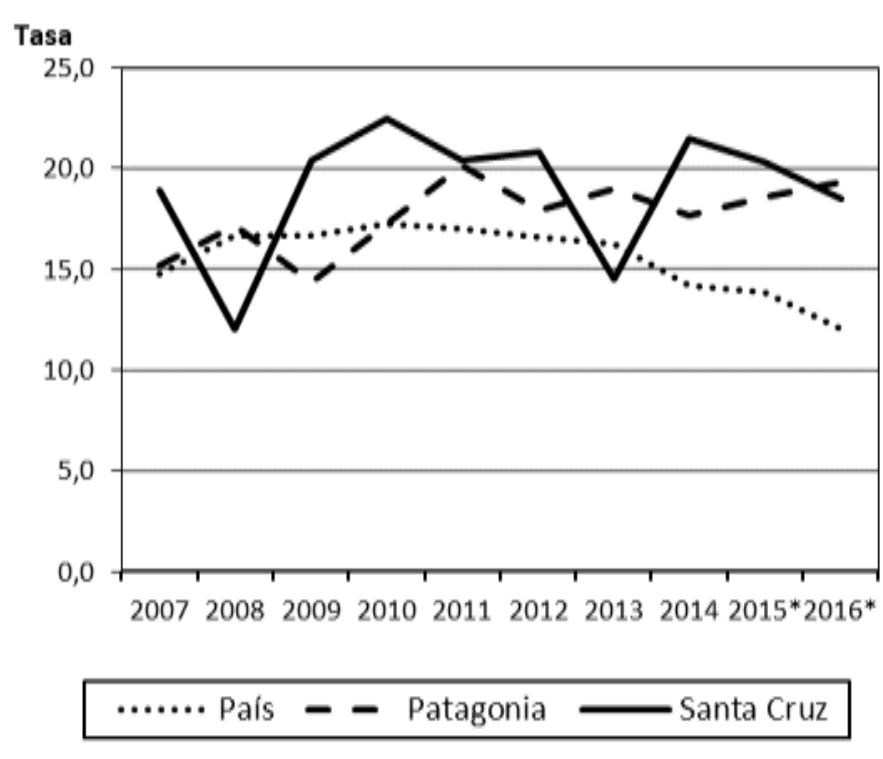

Fuente: Cuadro 2 del presente trabajo.

El Cuadro 3 informa sobre la razón varón/mujer, un indicador que permite conocer la paridad o disparidad entre sexos de personas diagnosticadas con VIH. El valor 1 significa igual cantidad de varones que mujeres diagnosticadas, y a medida que el indicador aumenta, refleja el predominio de varones respecto de mujeres con VIH.

Para Santa Cruz se registran valores inferiores al promedio del país en los tres períodos analizados y la brecha entre sexos es más estable. En particular, para el trienio 2014-2016, mientras que en Argentina el $71 \%$ de las personas diagnosticadas fueron varones, en Santa Cruz es de $64 \%$.

Con respecto a esta información, es necesario señalar que el género se incorpora a las fichas de notificación desde el año 2012, pero el organismo responsable de elaborar la información (la DSETHyT) considera que los datos de esta variable no tienen aún la calidad suficiente para poder analizarlos.

\section{Cuadro 3. Razón varón/mujer de VIH por años de diagnóstico agrupados según jurisdicción}

\begin{tabular}{lccc}
\hline Jurisdicción & 2008-2010 & 2011-2013 & 2014-2016* \\
\hline & 1,9 & 2,1 & 2,4 \\
Total país & 1,5 & 1,3 & 1,8 \\
Santa Cruz & \multicolumn{4}{l}{} \\
\hline *Años no cerrados por retraso en la notificación. \\
Fuente: Total de casos notificados a la DSETHyT por ficha epidemiológica. \\
Secretaria de Gobierno de Salud de la Nación. Argentina, 2018.
\end{tabular}

Con respecto al diagnóstico oportuno de sida en varones, la provincia presenta porcentajes muy superiores al promedio país y la región Patagonia.

En cuanto a las mujeres, el porcentaje de diagnóstico oportuno en Santa Cruz es similar al del país y se ubica levemente por debajo de la región. 
Cuadro 4. Porcentaje de personas con diagnóstico oportuno según sexo y jurisdicción Período 2012 - 2016*

\begin{tabular}{lcccc}
\hline \multirow{2}{*}{ Jurisdicción } & \multicolumn{2}{c}{ Varones } & \multicolumn{2}{c}{ Mujeres } \\
\cline { 2 - 5 } & Oportuno & Tardío & Oportuno & Tardío \\
\hline \multirow{2}{*}{ Total país } & 63,1 & 36,9 & 70,4 & 29,6 \\
Región Patagonia & 60,1 & 39,9 & 74,2 & 25,8 \\
Santa Cruz & 72,7 & 27,3 & 69,7 & 30,3 \\
\hline
\end{tabular}

*Años no cerrados por retraso en la notificación.

Fuente: Total de casos notificados a la DSETHyT por ficha epidemiológica.

Secretaria de Gobierno de Salud de la Nación. Argentina, 2018.

El cuadro 5 se ha elaborado calculando tasas trienales con el propósito de visualizar mejor la tendencia de los niveles de mortalidad por sida, dadas las variaciones de este indicador para la provincia debido al comportamiento irregular propio de una cantidad muy reducida de casos registrados.

La tasa de mortalidad para Argentina se mantiene estable en los cuatro períodos trienales analizados, con algunas oscilaciones en un proceso de leve disminución.

En tanto para Santa Cruz, y sin considerar el trienio 2005 - 2007 por registrar muy pocos casos, se observa una tendencia al aumento en los años 2008 a 2016. La tasa de mortalidad para el trienio 2014-2016 muestra un aumento porcentual de 7,5\% respecto al periodo 20082010.

No obstante, es importante señalar que las tasas de la provincia son significativamente inferiores a las tasas promedio del país. En el período bajo estudio, la tasa de mortalidad por sida en Argentina fue entre un $84 \%$ y un $96 \%$ superior a la tasa registrada en Santa Cruz.

Cuadro 5. Tasas brutas trienales de mortalidad por sida por 100.000 habitantes Ambos sexos, por jurisdicción. Período 2005 - 2016*

\begin{tabular}{lcccc}
\hline \multicolumn{1}{c}{ Jurisdicción } & $\mathbf{2 0 0 5 - 2 0 0 7}$ & $\mathbf{2 0 0 8} \mathbf{- 2 0 1 0}$ & $\mathbf{2 0 1 1 - 2 0 1 3}$ & $\mathbf{2 0 1 4 - 2 0 1 6}$ \\
\hline \multirow{2}{*}{ Total país } & 3,52 & 3,42 & 3,35 & 3,47 \\
Santa Cruz & 0,68 & 1,74 & 1,82 & 1,87 \\
\hline
\end{tabular}

Fuente: elaborado por la DSETHyT en base a datos provistos por la DEIS (Dir. de Estadísticas e Información de Salud). Secretaria de Gobierno de Salud de la Nación. Argentina, 2018.

Para finalizar con este breve diagnóstico referido al VIH en Santa Cruz, se considera oportuno presentar algunos datos correspondientes al año 2015 elaborados por el Ministerio de Salud de la provincia, que complementan la información hasta aquí analizada y permiten conocer la distribución de nuevos casos registrados en ese año según localidades de la provincia y además su composición por edad y sexo.

En el Gráfico 2 se puede observar que Río Gallegos concentra la mayor cantidad de nuevos casos ( $49 \%$ del total), situación acorde a la concentración poblacional que tiene esta localidad con respecto al total de habitantes de Santa Cruz y en segundo lugar se ubica una localidad muy pequeña en población como Cmte. Luis Piedra Buena ${ }^{4}$ con $17 \%$ de los casos.

Con menor participación figuran Caleta Olivia ${ }^{5}$ (segunda ciudad en importancia demográfica), Las Heras y Pico Truncado con $11 \%$, $9 \%$ y $8 \%$ respectivamente del total registrado.

\footnotetext{
${ }^{4}$ Según último Censo 2010, cuenta con 6405 habitantes.

${ }^{5}$ Según último Censo 2010, cuenta con 51733 habitantes.
} 
Las cinco localidades antes referidas concentran el $94 \%$ de los nuevos casos registrados en 2015.

Gráfico 2. Nuevos casos registrados por localidad. Santa Cruz, 2015

$(\mathbf{n}=\mathbf{5 3})$

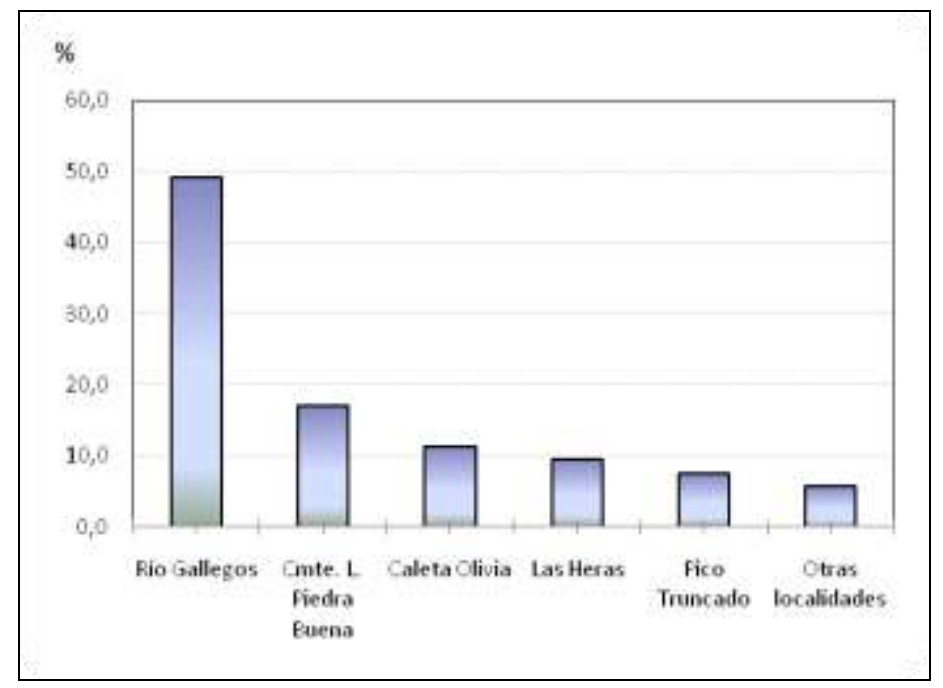

Fuente: Programa Provincial de VIH-SIDA e ITS. Ministerio de Salud. Provincia de Santa Cruz.

Al considerar la distribución por edad y sexo, el Gráfico 3 revela que el 68\% de nuevos casos corresponden a edades entre 20 y 39 años, es decir personas jóvenes y en cuanto al sexo, existe un claro predominio de varones en todos los grupos etarios, excepto para el tramo de edad de 10 a 14 años.

Este comportamiento es similar al que se observa en la región patagónica y en Argentina para esta enfermedad.

Gráfico 3. Nuevos casos registrados según edad y sexo. Santa Cruz, 2015

$(\mathbf{n}=\mathbf{5 3})$

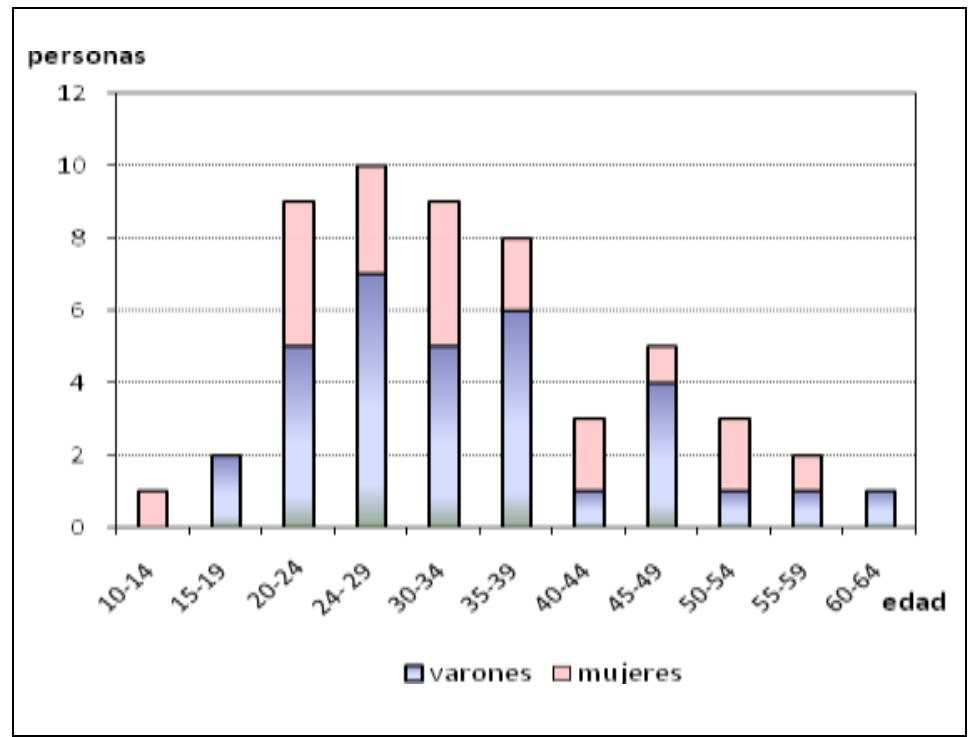

Fuente: Programa Provincial de VIH-SIDA e ITS. Ministerio de Salud. Provincia de Santa Cruz. 


\section{Marco conceptual}

El conocimiento científico es imprescindible para una intervención pertinente en esta temática. Existen conceptos que son precisos enunciarlos para su mejor comprensión. Para esto se recurre a los que proporciona ONUSIDA $^{6}$ por considerar que es una página de nivel internacional que publica para el resto de los países. Como son muchos los conceptos sobre la enfermedad, solo se seleccionan aquellos que se apuntan a comprender el trabajo aquí informado.

Cuando se habla del VIH se comprende que es el virus de la inmunodeficiencia humana quien causa la infección y el SIDA es su avance. El modo de trasmisión ocurre por medio de la sangre, el semen, el líquido preseminal, las secreciones vaginales y rectales o la leche materna de una persona seropositiva (que tiene el virus). Justamente la persona con diagnóstico positivo es seropositiva y puede suministrarse el tratamiento antirretroviral (TAR) que consiste en tomar medicación para tratar la infección. En este momento la persona está sometida a un tratamiento contra el virus por medio de una combinación de medicamentos. Si bien estos medicamentos no curan, “...los medicamentos contra el VIH pueden ayudar a las personas seropositivas a tener una vida más larga y sana. Los medicamentos contra el VIH también reducen el riesgo de la transmisión del VIH." (Onusida). A continuación se trascriben de la misma página conceptos a los efectos de no malinterpretar lo que en cada uno se expresa.

"Una meta importante del TAR es reducir la carga viral de una persona a un nivel indetectable, lo cual significa que la concentración del VIH en la sangre es demasiado baja para detectarla con la prueba de la carga viral. Las personas seropositivas que mantienen una carga viral indetectable realmente no presentan riesgo de transmitir la infección por el VIH a su pareja seronegativa durante las relaciones sexuales."

"Antes de empezar el TAR, las personas con el virus deben hablar con sus proveedores de atención médica acerca de los posibles efectos secundarios de los medicamentos contra el VIH y las posibles interacciones medicamentosas de este tipo de productos o con otros que la persona tome."

"En general, los beneficios de los medicamentos contra el VIH compensan con creces el riesgo de efectos secundarios. Además, los regímenes más nuevos contra el VIH causan menos efectos secundarios que los regímenes utilizados en el pasado."

"Sin tratamiento con medicamentos para combatirla, la infección por el VIH evoluciona a SIDA en un período de 10 años o más, aun cuando en algunas personas puede avanzar más rápido."

Estos conceptos dan cuenta que por medio del tratamiento y su adherencia, las personas seropositivas pueden tener una vida saludable.

\section{Marco teórico}

\section{Sistema de salud en la Provincia}

Río Gallegos es la capital de la provincia de Santa Cruz y se encuentra al sur de su territorio. Tiene una población total de 97.256 habitantes según último censo del año 2010 y es su centro político, económico y social. La provincia se constituye como tal luego de haber sido Territorio Nacional. Este acontecimiento ocurre en el año 1957 por medio de la Ley $\mathrm{N}^{\circ}$

\footnotetext{
${ }^{6}$ https://infosida.nih.gov/understanding-hiv-aids/fact-sheets/19/45/vih-sida--conceptos-basicos. Consultado el 11 de junio de 2019.
} 
14408. De este hecho trascendental se inicia la creación de los distintos establecimientos para la atención de los servicios propios de un Estado Provincial. La instalación de los hospitales se va incrementando a medida que la población se instala en su jurisdicción. Particularmente en la zona norte de la provincia se fundan instituciones de salud relacionadas con ramas específicas de trabajo y asociadas a empresas nacionales, como por ejemplo, el Hospital de YPF en Caleta Olivia, Servicios de Gas del Estado en Pico Truncado y de YCF en Río Turbio.

Actualmente el sistema de salud está compuesto hospitales públicos en cada una de las localidades y centros de salud. El hospital regional que se encuentra ubicado en la ciudad es inaugurado con nuevo edificio en el año 1995, cuenta con 220 camas, de complejidad VIII. Lo que significa que cuenta con Internación y complejidad en la atención, laboratorios, estudios radiológicos, etc.

Tras el transcurso de los años los lugares de atención a la salud y en virtud del incremento de la población y los cambios ocurridos a nivel nacional se crean nuevos centros, tanto públicos como privados. Estos sucesos se incrementan en el período de los años 1980 y 1990, año en que ocurren cambios estructurales en el país y que impactan en nuestra provincia (privatizaciones, descentralización, entre otras).

A partir de esta infraestructura sanitaria que permanece hasta la actualidad, se crean los Centros Integradores Comunitarios (CIC) por parte del Ministerio de Asuntos Sociales, actualmente es el Ministerio de Desarrollo Social. Desde estos centros se brinda a la comunidad, bajo el criterio de un abordaje integral en territorio, atención sanitaria y social.

En estos momentos existen en la ciudad de Río Gallegos centros de salud ubicados en diferentes lugares:

\section{Centros de salud en la ciudad de Río Gallegos de nivel provincial}

\begin{tabular}{|l|l|}
\hline Centro de salud & Barrio \\
\hline Centro de salud $N^{\circ} 1$ & Gregores \\
Centro de salud $N^{\circ} 2$ & Fátima \\
Centro de salud $N^{\circ} 3$ & Belgrano \\
Centro de salud $N^{\circ} 4$ & Del Carmen \\
Centro de salud $N^{\circ} 5$ & Barrio 366 viviendas \\
Centro de salud $N^{\circ} 6$ & ExYPF \\
Centro de salud $N^{\circ} 7$ & Gaucho Rivero \\
Centro de salud $N^{\circ} 8$ & San Benito \\
\hline
\end{tabular}

Fuente: Elaboración propia, 2019. Según datos proporcionados por Secretaría de Salud Comunitaria de la Municipalidad de Río Gallegos.

Sumado a esta infraestructura existen otros centros que dependen de la Secretaría de Desarrollo Humano, Dirección de Salud y Bienestar de la Municipalidad de Río Gallegos. 


\section{Dispensarios Municipales}

\begin{tabular}{|ll|}
\hline Centros & \multicolumn{1}{c|}{ Barrios } \\
\hline Dispensario $N^{\circ} 1$ & Gregores \\
Dispensario $N^{\circ} 2$ & Barrio 400 dptos. \\
Dispensario $N^{\circ} 3$ & Belgrano \\
Dispensario $N^{\circ} 4$ & Del Carmen \\
Dispensario $N^{\circ} 5$ & Barrio 366 Viviendas \\
Dispensario $N^{\circ} 6$ & Gaucho Rivero \\
Dispensario $N^{\circ} 7$ & San Benito \\
\hline
\end{tabular}

Fuente: Elaboración propia, 2019. Según datos proporcionados por Secretaría de Salud Comunitaria de la Municipalidad de Río Gallegos

Como se puede observar en los cuadros existen un número significativo de centros de salud ubicados en los barrios. A estos se suman una clínica privada, centros de atención que pertenecen a obras sociales (camioneros, comercio) y consultorios privados.

Desde lo sanitario existen un número significativo de centros en relación con la población existente en la ciudad.

\section{Políticas Públicas Sociales}

Se concibe que el programa de VIH-Sida tal cual se encuentra normado garantiza un derecho como lo es el de salud, con foco en la atención a las personas que conviven con el virus. Esta perspectiva, de derechos, se basa en principios y estándares internacionales que son regulaciones, sistemas y entidades por medio de las cuales el Estado debe crear oportunidades y fortalecer instrumentos bajo criterios de equidad, integración social, respeto y protección. Esto significa que se encuentra definido con mayor precisión no sólo aquello que el Estado no debe hacer a fin de evitar violaciones de derechos, sino también aquello que sí debe, a fin de lograr la plena realización de los derechos civiles y políticos (DCP) y también los derechos económicos, sociales y culturales (DESC). De esta manera se piensa en superar la visión y el enfoque sesgado con el que se han venido implementando las políticas públicas sociales, las que han sido planteadas desde la oferta de beneficios asistenciales, discrecionales.

Los DDHH son pensados en la actualidad como un programa que puede guiar u orientar las políticas públicas de los Estados y contribuir a las estrategias de desarrollo e inclusión social. La satisfacción de DESC resulta indispensable para la existencia de DCP que requieren al menos una situación de superación de las necesidades humanas básicas para ser ejercidos plenamente y que inversamente los DCP son indispensables como mecanismos de control del cumplimiento de las obligaciones que emanan de los Derechos Económicos Sociales y Culturales y como garantías para el goce de una institucionalidad democrática (Abramovich y Courtis; 2006).

En el programa de atención a las personas que conviven con el virus, sus derechos son reconocidos en la atención de su salud y su cuidado. Se organiza un espacio para su ejecución con criterios de notificación del diagnóstico positivo, entrega de medicamentos y atención en horarios para controles médicos en forma periódica. En este sentido las personas que son atendidas necesitan organizar su vida para dar lugar a nuevos cuidados que requiere el 
tratamiento. Adelantado (1998) ${ }^{7}$ avanza en este punto aportando que una política social, al ser ejecutada, se interpone en las prácticas sociales. Estas últimas se conciben como las formas de hacer alguna cosa y que son compartidas con los demás. De esta interacción construyen representaciones, formas de pensar, entre otras (Sánchez Vásquez, 2003). En este caso es la forma de llevar adelante la ejecución del programa, bajo determinados criterios y organización, lo cual puede interpelar las prácticas sociales que se vienen desarrollando. Pero por medio de nuevas prácticas que se van desplegando ante una necesidad, se pueden introducir cambios que se orienten a producir nuevas prácticas sociales. Cuando esto ocurre se pueden sostener y lograr una más profunda y amplia cobertura porque se direccionan a nuevos instituidos. Desde este punto de vista se posiciona que, las prácticas sociales, forman parte de la estructura social.

Justamente la estructura social, está integrada por instituciones y grupos interrelacionadas entre sí por medio de las prácticas sociales, lo cual genera desigualdades entre ellos "...la estructura social sería la configuración de instituciones, reglas y recursos que atribuye condiciones de vida desiguales a las personas en un momento y un lugar determinado." (Adelantado, 1998:127).

Pero estas condiciones de vida desiguales no son estáticas porque los grupos poseen cierta autonomía y pueden provocar cambios que impacten en su posición social. En este sentido ya no se puede discurrir que una política social se direccione en un solo sentido, sino concebir que en la estructura social al objetivarse en prácticas sociales que interrelaciona las instituciones y grupos sociales, sus postulados son interpretados y ejecutados desde lo instituido. Una forma de conocer estas prácticas sociales es desde un punto de vista analítico, porque en la realidad no se encuentran separadas. Una de estas formas es pensar desde esferas sociales. Desde estos conceptos se pueden separar distintos conjuntos de actividades en el ámbito social que las personas llevan a cabo para resolver sus necesidades. Estas esferas son regiones sociales que poseen su propia dinámica y posibilitan distintas intervenciones y aporte. Ellas son: mercantil, que se refiere a la producción e intercambio mercantil; doméstica-familiar, referida a todas aquellas actividades necesarias para mantener un hogar (cuidado de personas, limpieza, cocina, etc); estatal, propias de todo Estado como responsable de la organización y orden por medio de sus instituciones y organizaciones; relacional, "como aquella compuesta por las acciones sociales supraindividuales que canalizan intereses y necesidades (no solo materiales) de las personas, mediante distintos grupos sociales distribuidos en asociaciones formales y en grupos comunitarios (informales)." (ídem, 135).

Por medio de estas esferas se puede investigar las consecuencias que puede o no abarcar una determinada política social. En nuestro tema de investigación, el programa de Vih-Sida se direcciona hacia la esfera estatal desde la salud pública, pero no se debe desconocer la incidencia en las otras esferas porque la vida de la persona se ve modificada ante la confirmación del diagnóstico positivo. A nivel social están presentes representaciones sociales, prejuicios hacia la persona que porta el virus y desde las cuales se instituyen prácticas sociales de discriminación que repercute en las esferas doméstica, mercantil y relacional para llevar adelante el tratamiento requerido por la enfermedad que es, por el momento, un tratamiento de por vida.

Desde esta perspectiva de análisis, las prácticas sociales no son naturales sino que son construcciones históricas. Para que esto suceda el sujeto junto a otros, tienen un rol fundamental en la participación y acciones conjuntas para que las transformaciones ocurran y puedan mantenerse en el tiempo.

\footnotetext{
${ }^{7}$ El autor se basa en el concepto de estructuración de Giddens pero también aporta en el sentido de las prácticas sociales Bourdieu por medio de los conceptos de campo y habitus. (Bourdieu, 1980, 2002, 2007)
} 


\section{Las organizaciones no gubernamentales}

En esta línea de argumentación que se viene desarrollando entre la relación política social y práctica social, en la cual la participación de los sujetos sociales es importante para introducir cambios en lo instituido, que apunten a una mayor integración de las personas que conviven con el virus en la sociedad. A nivel social existen organizaciones de personas que apuntan a diferentes objetivos y se denominan Organizaciones no Gubernamentales (ONG), espacios desde donde es posible ampliar la difusión sobre la temática que apunten al mismo objetivo, el de modificar prácticas sociales.

Una organización está compuesta por personas que comparten un mismo objetivo. Para ello se organizan los recursos para desempeñar su tarea, se organizan en diferentes actividades, presentan un proyecto que puede o no estar escrito pero que le brinda identidad, cultura organizacional, entre otras. En toda organización y no importa su tamaño se encuentran estos elementos básicos (Schlemenson, 1996). Pero estás se encuentran en un espacio social con el cual entabla relaciones porque hacia ella se dirige e intercambia sus productos, resultados y se encuentran sus integrantes y destinatarios.

Éstas a su vez pueden o no perseguir un beneficio económico. Lo que aquí interesa es centrarse en el conocimiento de aquellas organizaciones no gubernamentales (ONG) que no persiguen fines de lucro. Actualmente también se las conoce como tercer sector porque son parte de la sociedad civil y que, desde nuestro punto de vista, se orientan al bienestar común ${ }^{8}$.

En el sentido de encontrarse en un contexto social, significa que las decisiones que se adoptan desde el Estado las puede afectar de alguna u otra manera, y a su vez ellas pueden influir por medio de sus reclamos o para proponer cambios, aunque esta posibilidad no forma parte de su constitución en sí. En este sentido las ONG se encuentran afectadas y a su vez podrían afectar al Estado desde su nivel de injerencia.

Esta relación que se establece entre el Estado y las ONG tiene distintas relaciones en diferentes países y que responden a la forma en que se van constituyendo e interviniendo en lo social, así como el lugar que le brindan distintos gobiernos. En este sentido se pueden citar tendencias en diferentes países. Wolfe (citado en Thompson, 1995) expresa que: 1) Organizaciones sin fines de lucro que recibe su presupuesto desde el Estado para su funcionamiento a fin de cumplir sus objetivos. Sobre todo se produce en los Estados Unidos. 2) ONG que funcionan sin injerencia del Estado y 3) aquellas organizaciones que funcionan en forma mixta, es decir reciben apoyo del Estado pero los aportes lo logran también por medio de pago de cuotas, donaciones, etc. Se podría decir que en la forma tres son las que se encuentran en el funcionamiento los Ong en el país, en su gran mayoría.

"En la actualidad existen numerosas instancias de convergencia entre organismos del Estado y OPFSL (ONG para este escrito) en el diseño, implementación y evaluación de programas. A ello han contribuido factores endógenos y exógenos. Respecto al primero, el escenario de crisis social que ha sobrevenido con posterioridad a las reformas del Estado en diversas áreas, la descentralización de las políticas sociales y la necesidad de atender en forma eficiente las diversas demandas sociales, han generado condiciones para que en distintas instancias gubernamentales se instrumenten programas en los que se plantea la incorporaciones de la sociedad civil. Con respecto a los factores exógenos, la presencia de agencias multilaterales de crédito y organismos privados de cooperación al desarrollo han contribuido de manera muy marcada a acelerar esta tendencia" (Thompson, 1995:23).

\footnotetext{
${ }^{8}$ El primer sector se nomina al Estado y el segundo sector al mercado donde se encuentra la relación de oferta y demanda y los servicios.
} 
En la ciudad de Río Gallegos, se encuentran diferentes tipos de organizaciones no gubernamentales que persiguen distintos tipos de objetivos y que se dirección hacia un determinado sector, a saber: asistencia social, discapacidad, deportes, entre otras. Para lograr sus objetivos desarrollan diferentes estrategias, cobrar cuota para pertenecer a la organización o para realizar la actividad que ofrecen o reciben aportes por parte del Estado Provincial.

Con estos apuntes desarrollado sobre las Ong, su ubicación, relación con el Estado y conformando la estructura social, se constituyen en espacios posible de desplegar actividades sobre la temática del Vih-sida para el cuidado personal y, como ya se dijo, que apunten a cambios de comportamiento cultural.

\section{Marco legal}

Complementando con lo anterior y que fundamenta el reconocimiento de derechos por medio de legislaciones, existen en el país distintas leyes que se complementan con lo normado en la Ley $N^{\circ} 23798$ en la atención hacia la persona que convive con el virus y en este apartado se nombran algunas de ellas.

El Derecho a la Salud es un derecho que alcanza rango constitucional en el año 1994, a partir de la modificación de la Carta Magna mediante la incorporación de las Declaraciones, Convenciones y Pactos Internacionales sobre los Derechos Humanos. Acontecimiento que sostiene todo el sistema de atención sanitaria para la población en general. Se postula que el Derecho a la salud tiene preferencia sobre los intereses comerciales.

La antes mencionada Ley $\mathrm{N}^{\circ} 23798$ en sus articulados y Decreto reglamentario 1244/90 establece la lucha contra el Vih y el sida en forma integral reconociendo la investigación, atención gratuita y estrega de medicamentos, tratamiento y educación. Además del respeto de la dignidad humana en pos de la no discriminación; el derecho a la información sobre el estado de salud y los efectos que puede producir su tratamiento, confidencialidad, no difusión de la identidad de las personas que se encuentran en tratamiento y la prevención para un cuidado responsable de la persona sobre las formas de trasmisión.

En base a esta ley y en el año 1995, se crea el Programa Nacional de lucha contra el Sida y retrovirus del humano. Actualmente es responsable la Dirección de Sida y Enfermedades de Transmisión Sexual, la cual define y coordina las políticas de prevención y atención del VIHsida y otras infecciones de transmisión sexual, articulando sus acciones con los Programas Provinciales y jurisdiccionales, sociedades científicas, actores de la sociedad civil y organismos internacionales.

Otras leyes que se consideran se vinculan en forma directa con esta, ley 24.754 del año 1996 que obliga a las empresas de medicina prepagas a atender a sus afiliados que conviven con el virus. La Ley 25.543, que se promulga en el año 2002 tiene como objetivo el acceso al Test diagnóstico del virus de inmunodeficiencia humana y Obligatoriedad del ofrecimiento a toda mujer embarazada como parte del cuidado prenatal normal. El VIH puede transmitirse durante el embarazo, el parto o la lactancia, de la mamá al bebé, es por eso que todos los establecimientos destinados a la salud, públicos o privados, están obligados a cubrirlo ya que a partir de los resultados obtenidos se pueden poner en marcha tratamientos efectivos que reduzcan esta posibilidad.

Otras leyes que se vinculan en forma indirecta, se direccionan al conocimiento y cuidado en la sexualidad humana, es ley 25.673 Programa Nacional de Salud Sexual y Procreación Responsable, creación en el ámbito del Ministerio de Salud. Esta ley pretende alcanzar el nivel más elevado de salud sexual, con el fin de que la persona pueda adoptar decisiones libres de discriminación, coacciones o violencia. En el año 2006 se Promulga La Ley 26.150 
Programa Nacional De Educación Sexual Integral siendo uno de sus propósitos promover la comprensión y el acompañamiento en la maduración afectiva del niño, niña y adolescente ayudándolo a formar su sexualidad y preparándolo para entablar relaciones interpersonales positivas.

A partir del año 2013 se modifica la manera de informar el código para la notificación epidemiológica siendo las dos primeras letras del primer nombre y las dos primeras letras del primer apellido más la fecha de nacimiento.

Por Res. 270/2015 Ministerio de Trabajo, Empleo y Seguridad Social de la Nación, se establece la prohibición de incluir la prueba de VIH en los exámenes preocupacionales. Todas las personas tienen derecho a acceder a un trabajo sin discriminación.

Como se puede vislumbrar existen leyes sobre la atención hacia la persona que convive con el virus y leyes que reconocen el derecho a la educación sobre sexualidad y que norman formas de intervenir desde distintas estamentos del Estado.

\subsection{Resultados análisis y discusión}

\section{Materiales y métodos}

\section{$\underline{\text { Instrumentos de recolección de datos }}$}

Se trata de un estudio descriptivo centrado en la implementación del programa de VIH-SIDA en Río Gallegos, provincia de Santa Cruz y su impacto en la vida de las personas que cuentan con diagnóstico positivo que son atendidos desde un período de tiempo de dos años, 2015 2017. El lugar físico donde se encuentra funcionando el programa es el hospital regional de Río Gallegos. Las personas que conviven con el virus y son atendidas desde el programa significan que no cuentan con obra social.

Los propósitos centrales se expresan en los objetivos que es describir la forma en que se aplica el programa en las organizaciones estatales y en las organizaciones no gubernamentales y su posible relación entre ambas. Además de conocer el nivel de conocimiento que poseen las personas de la ciudad hacia la temática del Vih-sida. Sumado a estos objetivos, conocer las necesidades que presentan las personas que conviven con el virus y las estrategias ${ }^{9}$ que implementan en su vida cotidiana para la atención y controles médicos y si estos organismos contemplan en sus servicios para dar respuesta. Con respecto al corte temporal, no fue necesario establecer una diferenciación respecto a otros años porque el programa ante el cambio de gobierno nacional, continuo con las prestaciones según lo planificado ${ }^{10}$.

Con la finalidad de recopilar datos y elaborar información sobre la implementación del Programa Provincial VIH-Sida, se han diseñado diferentes instrumentos para los siguientes objetivos:

a) Recolección de datos vinculados con las autoridades responsables en la implementación del programa y a las personas que se desempeñan en el lugar de ejecución.

\footnotetext{
${ }^{9}$ Estrategia en el sentido que propone Matus desde la planificación estratégica. Esta autor expresa que un actor social puede proponer desde su posición distintas formas de acciones, actividades para el cambio o poder expresar la forma de su poder en una determinada situación. A esto llama estrategia. (citado en Wagner, Alejandra, 2006)

${ }^{10}$ Lo expresado por los responsables del programa, es que los medicamentos fueron enviados en forma regular aunque a hay meses que se retardan en su suministro.
} 
b) Identificación y entrevistas a responsables de organizaciones no gubernamentales.

c) Diseño del cuestionario que luego se aplica a las personas que son atendidas desde el programa provincial.

d) Diseño de cuestionario para entrevistar a personas de la comunidad.

En el punto a) se diseña una entrevista con preguntas cerradas y abiertas siguiendo los artículos que propone la Ley y su reglamentación. Bajo este criterio es posible indagar sobre la ejecución del programa teniendo en cuenta lo normado. La entrevista es suministrada a la autoridad máxima responsable de la aplicación del programa en la Provincia. Este programa actualmente depende de la Subsecretaría de Salud Comunitaria que depende del Ministerio de Salud de la Provincia. También se suministra, el mismo instrumento, a la responsable directa del programa en la ciudad de Río Gallegos, con el objeto de conocer la aplicación del programa en contacto directo con la persona atendida. Por otro lado se concreta una reunión con el personal que conforma el Departamento de Investigación y Docencia del Hospital Regional de la ciudad a fin de indagar la factibilidad de ejecutar parte del proyecto de investigación en el ámbito hospitalario, ya que este departamento es el responsable de autorizar este tipo de tarea.

Se entrevista, además, a personal que antiguamente se desempeñó en el programa para consultar datos sobre su historia en diferentes momentos histórico, con el objeto de reconstruir desde sus voces, el proceso de su constitución.

Para el punto b) se diseña un cuestionario para su aplicación a las organizaciones no gubernamentales. El objetivo es recopilar datos sobre la organización, actividades, características de sus destinatarios y si realizan actividades de difusión u otro tipo de tareas referidas al tema en cuestión y por último si sería posible implementar actividades desde el programa de VIH-Sida. Para esto se seleccionan las ONG más representativas de la ciudad de Río Gallegos, considerando su trayectoria, tiempo de actividad en el medio y alcance de sus actividades (asociaciones deportivas, sociales, de asistencia sanitaria, socio-educativas, etc), a las que concurren distintos grupos etarios. En total se contabilizan 14 ONG.

En cuanto al punto c) desde el inicio de la investigación se acuerda un trabajo en conjunto con personal que se desempeña en el programa provincial VIH-Sida.

Este equipo de investigación siempre tuvo presente el carácter confidencial que tiene la información de toda persona con esta enfermedad, teniendo en cuenta la reglamentación $\mathrm{N}^{\circ}$ 1244/91 de la Ley 23798 que dice: “Art. 2. Inciso c) — Los profesionales médicos, así como toda persona que por su ocupación tome conocimiento de que una persona se encuentra infectada por el virus HIV, o se halla enferma de SIDA, tienen prohibido revelar dicha información...". Pero en el transcurso del trabajo y al momento de concretar la encuesta, se presentan requerimientos por parte de la Dirección de Docencia e Investigación respecto a los criterios que ellos solicitan para implementar una investigación en el ámbito hospitalario y respetar la confidencialidad de las personas que portan el virus y son atendidos en el programa.

Por esto solicitan cumplimentar con los criterios de investigación según su protocolo y que la encuesta se lleve a cabo por medio del médico Infectólogo. Como los requisitos del protocolo son distintos a los requeridos por la Universidad se decide que, si se cumplimentan llevaría más tiempo y el acceso a las personas para la encuesta no estaría garantizado, pues depende del criterio de los profesionales médicos que trabajan en el programa y estos facultativos despliegan tareas específicas con las personas que son atendidas para el control clínico. Por lo cual las preguntas que las personas deben responder se verían condicionadas. 
Ante los límites expresados por las autoridades del equipo de salud correspondiente, para implementar la encuesta a las personas que conviven con el virus, se resuelve un cambio en la implementación del instrumento encuesta prevista.

El cambio de estrategia es aplicar una entrevista con preguntas abiertas a las personas que se puedan identificar según conocimiento del personal que pertenece al grupo de investigación u otras personas que tiene contacto con las personas en tratamiento y que expresen su voluntad de contestar. La utilidad de esta técnica es que aporta datos para analizar la aplicación del programa desde el punto de vista personal por lo cual no es posible generalizar sus resultados, pero si dar información sobre su ejecución. Las preguntas de la entrevista se relacionan con la encuesta elaborada, datos filiatorios, actividades diarias, forma de atención en el programa, dificultades u obstáculos que se presentan para el acceso a los distintos controles que deben realizar. En total y considerando el resguardo de la Ley de no darse a conocer las personas en tratamiento, se puede identificar a tres personas que acceden voluntariamente a contestar la entrevista.

Por último en el punto d) se realizaron un total de 53 encuestas por parte de los estudiantes de la Carrera de Trabajo Social, siguiendo la pauta que los entrevistados sean familiares o miembros de su círculo cercano, dentro de un rango de edad entre 19 a 60 años de edad ${ }^{11}$. La muestra en este sentido es intencional porque el objetivo es contar con información de la comunidad sobre el tema del VIH-Sida, que nos puedan dar un conocimiento general de lo que piensan a nivel social sobre el tema.

\section{Fuentes de información secundaria}

En cuanto a la organización del trabajo para la conformación del corpus teórico y empírico se trabajan con distintos tipos de fuentes y son las que a continuación se detallan.

Como se trata de un tema ampliamente estudiado en el país, en una primera etapa se recogen aquellos que se consideran pertinentes para el tema en estudio. Los estudios reunidos indagan sobre temas estadísticos, como cantidad de personas que conviven con el virus, de personas que han contraído el sida, las variables que inciden en la discriminación, entre otras. Esta etapa es de utilidad para la confección de los antecedentes.

Por otro lado se examina la composición del sistema de salud para delimitar el contexto donde ubicar los diferentes efectores de salud existente en la ciudad e identificar distintas ONG por medio de la selección explicitada en párrafos anteriores.

Se trabaja con bibliografía y documentos publicados de autores locales para la confección de la historia de la ciudad y su composición. Para los datos sobre investigaciones sobre el VIHSida, se consultan bibliografía específica a nivel nacional, sitios Web especializados como ONUSIDA, Ministerio de Salud de la Nación por medio de las publicaciones de la Dirección de Sida, ETS, Hepatitis y TBC y de Fundación Huésped. Y bibliografía específica sobre políticas públicas con enfoque de derechos.

\section{Resultados}

Los datos que a continuación son analizados se apoyan en las entrevistas a las máximas autoridades responsables de la ejecución del programa en la provincia con información de tipo cualitativa que brindan los pacientes, con el objeto de entrecruzar ambas.

\footnotetext{
${ }^{11}$ El presente trabajo se lleva a cabo por medio de una encuesta realizada por estudiantes de la Licenciatura en Trabajo Social, en el marco de un trabajo práctico integrador en el espacio curricular Políticas Públicas. Año 2018 (Octubre-Noviembre)
} 
De acuerdo a la información brindadas por las autoridades de salud, se inicia la atención en el Programa Provincial del Vih-sida con la detección positiva del virus en sangre en una persona. Pero esta positividad tiene dos pasos: la detección del virus en una primera etapa que ocurre por análisis de sangre, testeo rápidos o análisis de maternidad. Luego se lleva a cabo un análisis confirmatorio. Si este último es afirmativo concurre al servicio e ingresa como paciente del programa en caso de no tener obra social.

...tras el análisis confirmatorio de la presencia del virus en sangre, el Infectólogo notifica y esta el psicólogo, aunque su presencia depende de la situación. Algunos sospechan otros no. (Personal del programa)

Por otra parte, de la entrevista a las personas que conviven con el virus se obtiene la manifestación de cómo se enteran de su diagnóstico y expresan las vías de confirmación:

Me entere durante el embarazo, ya que ahí te hacen a prueba de control, un día me llamaron que me tenía que presentar al hospital en el consultorio ... y ahí me dieron la noticia, en ese momento estaba un psicólogo y una infectologa. (Entrevista 1).

... cuando mi señora dio positivo durante el embarazo,...me pidieron la prueba a mí y salió positivo. (Entrevista 2).

En estas situaciones se presenta la confirmación por medio de un diagnóstico de embarazo y en el otro se detecta el virus tras el test positivo de su pareja. En estas se manifiesta la utilidad en este tipo de intervención prevista porque la pareja de la mujer embarazada desconocía que era portadora del virus.

La etapa siguiente al diagnóstico, el médico Infectólogo notifica de la presencia del virus en sangre y se evalúa si es o no necesaria la presencia del psicólogo. Este profesional actúa en caso de ser necesario ante la reacción de la persona por el diagnóstico positivo.

Luego se realiza la atención médica clínica en caso de ser necesario, atención psicológica cuando lo demanda, control del Infectólogo y atención social en caso de solicitar. Este último aspecto es cubierto por un trabajador social que pertenece al Trabajo Social del Hospital ya que el servicio no cuenta con un profesional propio. En este punto se tiene en cuenta la decisión personal del modo de llevar adelante la intervención.

Sobre el punto de atención psicológica en la entrevista (le ofrecieron)... el día que me dieron el diagnostico, después nunca más lo vi, en esos días que estuve re mal lo necesitaba, ahora ya no, porque lo pude hablar con familiares y amigos, algunos lo entendieron, otros se alejaron y muchos se enojaron cuando supieron ... (Entrevista 1).

... me ofrecieron ayuda psicológica pero para conseguir un turno debes ir a las 04 de la mañana y a veces no conseguís, la verdad te cansas y no vas más. (Entrevista 2)

En lo que respecta a la atención tanto psicológico como clínica, los pacientes expresan necesitarla, pero manifiestan que el programa no asegura el proceso a través del tiempo para otorgar los turnos correspondientes. Esto puede deberse al obstáculo de conseguir los mismos, ir a las 4 de la mañana y pareciera no existir un sistema para facilite la atención cuando el paciente lo necesita desde el momento del diagnóstico positivo. Y así se cansan y van abandonando este tipo de tratamiento. La contención que dicen necesitar la pueden resolver hablando con parientes o amigos pero esto depende de que acepten la condición de persona conviviendo con el virus, caso contrario se alejan.

Por otra parte se tiene en cuenta a un agente sanitario cuando el paciente no puede trasladarse por cuestiones de salud. Esta acción está en vinculación directa con el trabajo sobre la adherencia al tratamiento. Otros criterios para el trabajo en la adherencia al tratamiento son: 
Los registros de los pacientes en su historia clínica, que porte el carnet hospitalario, el control de la carga viral, al menos cada 15 días. Si los valores aumentan se entrevista a la persona. (Personal del programa)

Comprender y saber lo que le ha sucedido es muy importante el contar con información, como lo atestigua el siguiente párrafo

...ahora la infectologa me explico que no se contagia por tocar a una persona, tomar un mate, a mí eso me daba mucho miedo, también me dijo que gracias al avance de la medicina la calidad de vida mejoró, que puedo hacer una vida normal... (Entrevista 1).

Para dar continuidad al tratamiento los controles las realiza el médico Infectólogo y este puede ir variando la medicación conforme la edad de la persona, la evolución del virus en sangre y las consecuencias que produce la toma sistemática de la medicación. La medicación que se entrega consiste en antirretrovirales y antibióticos. Además y en el caso de la madre se entrega azt y leche maternizada pues se inhibe la lactancia. El tiempo de entrega de los medicamentos es en forma mensual, aunque a veces varía según la evolución de la enfermedad y a criterio del médico Infectólogo.

En entrevista nos hicieron un test de resistencia y automáticamente empecé a tomar el retro viral para evitar que mi bebé nazca enfermo y por suerte nació bien, sin presencia de virus, ya le han realizado tres pruebas y las tres vinieron negativo. (Entrevista 3 ).

...las pastillas me matan el estómago, pero no conseguís turno para el gastroenterólogo así que me las aguanto nomas, trato de comer menos, igual la doctora me dijo que tengo que hacer dieta porque estoy excedida de peso, la mayoría dice que el enfermo de VIH adelgaza en mi fue al revés engorde, (plantea entre risas.) (Entrevista 1)

...cuando mi señora estaba embarazada nos atendieron de diez ellos nos llamaban todos los días, nos conseguían la medicación, turnos nosotros no teníamos que hacer nada, una vez que el bebe nació nos soltaron la mano... (Entrevista 2).

Si bien la entrega de medicamentos es mensual y se puede cumplir con la entrega, el impacto de los medicamentos puede traer consecuencias en la salud. En este caso el paciente debe ser atendido por el especialista correspondiente, pero el hecho de no conseguir turnos impide la atención en el tiempo requerido. Se presentan también situaciones que se vinculan en la atención y que es vivida por las personas en tratamiento como una forma de no contar con el apoyo que ellos sienten deben brindar el personal que se desempeña en el programa.

Los medicamentos se entregan en forma mensual. Este hecho despierta distintos sentimientos en la persona al ir a buscarlos, por parte de las personas que se encuentran esperando ser atendidas en el nosocomio por los distintos profesionales. Despierta en las personas infectadas sentimientos de ser mirados y hasta condenados por su situación: la gente te mira feo, cuando vas a retirar el remedio o a pedir un turno. (Entrevista 3)

Como el resguardo de la identidad de la persona que convive con el virus está reglamentado legalmente, desde el programa han decidido llevar la historia clínica en resguardo en el servicio, de esta forma solo tiene acceso al mismo el médico Infectólogo y el médico clínico.

Otro requerimiento que se encuentra reglamentado es la información de los casos nuevos y los fallecimientos por sida. En esta situación en el manejo de los datos estadísticos existe un sistema que corresponde al área provincial donde se vuelcan los datos de los pacientes por medio del programa provincial y en el cual es notificada la parte interesada pero no se lleva a cabo vigilancia de salud. Luego con esta información se confeccionan la estadística del año que es compartido con las autoridades nacionales. 


\section{Difusión de la temática}

Otro aspecto del programa normado por la ley y en su reglamento, es la difusión para el conocimiento a la comunidad sobre la forma de contagio del virus. Esta acción se puede entender que apunta a la prevención. Por medio de los datos que se cuenta, desde el programa provincial, no se llevan a cabo talleres destinados a la comunidad. Solo se actúa en caso de pedidos de instituciones del medio. No es posible informar la cantidad de los mismos porque no se cuenta con esa información en cifras sino que más bien depende de los pedidos que se recepcionan y estos varían en el tiempo. Por ejemplo pueden ser organizaciones de acción social, universidad. Sí, se realizan encuentros hacia los profesionales de la salud como enfermeras, médicos y el resto del personal de los centros de salud, a modo de actualización sobre la temática. Por otro lado y desde la subsecretaria de Salud Colectiva informan que desde Nación tampoco se ha realizado capacitación para el personal que se desempeña en el sector; solo han enviado folletería, material didáctico y la cobertura para la entrega de la medicación necesaria.

En los establecimientos educativos se realizan charlas o talleres si estos solicitan. De esta modalidad han llevado a cabo charlas o talleres en establecimientos de nivel secundarios. Según la entrevista, en el año se pueden llevar a cabo estos encuentros pero tampoco es posible cuantificarlos, porque depende del pedido de los establecimientos. Generalmente son los colegios secundarios quienes solicitan y en estos establecimientos concurren alumnos de entre 13 a 17 años aproximadamente, franja etaria que son sus destinatarios. Estos talleres son coordinados por las enfermeras del servicio y a veces participa el psicólogo.

A nivel público se realizan campañas por los medios de comunicación en forma periódica participando de distintos programas que son invitadas o por medio de entrevistas que son publicadas en los diarios locales y participan en actividades que se implementan en la ciudad como festejo de la primavera, el día mundial del sida. También se utilizan folletos impresos que son diseñados desde esta instancia provincial, Subsecretaría. Estos folletos son entregados en distintas organizaciones del medio como clínicas, universidad, comercios, etc. Una última actividad prevista es la entrega de lubricantes, preservativos, etc. todos estos elementos son provistos por el Ministerio de Salud de la provincia a través del programa de prevención. Estos son provistos por medio de dispenser ubicados en el campus universitario cercano a los baños, en la sede del programa, en sectores del hospital, en la sede de la cruz roja de la ciudad. No se puede extender este tipo de iniciativa porque en los demás espacios sociales no aceptan instalar dispenser. Según el boletín sobre VIH-Sida $\mathrm{N}^{\circ} 35$ en la provincia han aumentado los lugares de distribución de preservativos.

\section{El rol de las Organizaciones No Gubernamentales}

Con la finalidad de conocer el rol de las Organizaciones No Gubernamentales (ONG) y su vinculación con los programas de VIH-Sida se lleva a cabo un relevamiento de 14 organizaciones que desarrollan actividades en Río Gallegos.

Entre otros aspectos evaluados, se ha podido establecer que $71 \%$ de las ONG tiene más de 45 destinatarios, en su mayoría personas jóvenes y adultas, seguidos por el grupo de adolescentes.

El perfil por edades antes señalado se presenta en el siguiente Gráfico 4: 
Gráfico 4. Distribución de la edad de personas atendidas por ONG de Río Gallegos. Año $2019 \quad(\mathbf{n}=53)$

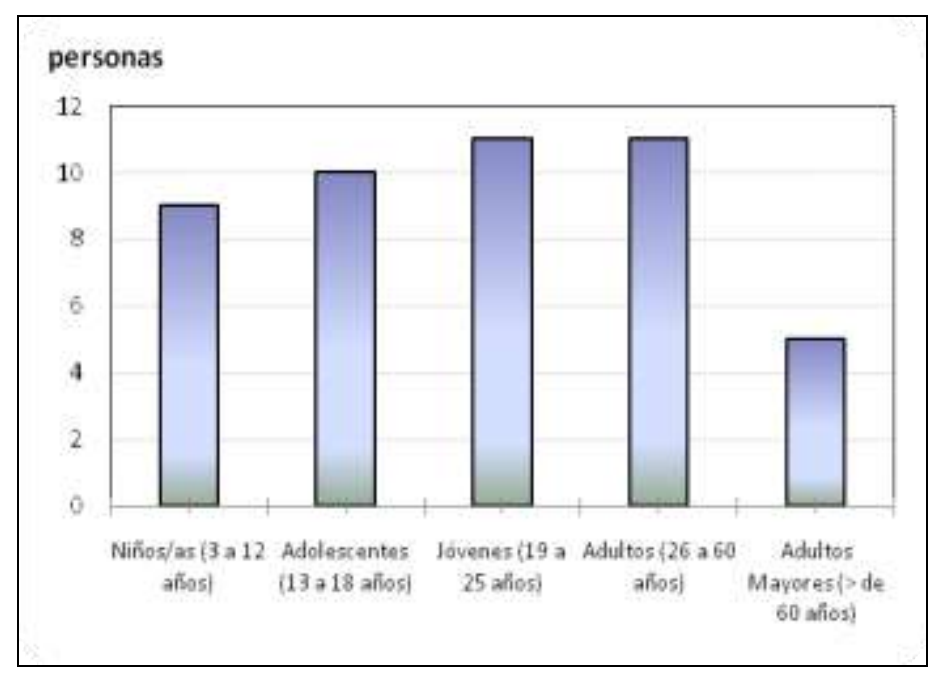

Fuente: Encuesta realizada por Equipo de Investigación. Elaboración propia

Analizando la relación de estas ONG con las distintas políticas públicas sociales, se observa que la mitad de ellas articulan sus objetivos y acciones institucionales con diferentes programas gubernamentales. En particular pueden mencionarse programas y/o actividades como: fortalecimiento para clubes; educación sanitaria, Juegos Evita, programas de Sedronar.

El 71\% de las organizaciones tienen conocimiento de la existencia de políticas públicas sobre la enfermedad, y todas ellas realizan acciones vinculadas de prevención, difusión y detección, contempladas en el programa provincial de VIH-Sida.

Las actividades concretas se orientan a controles médicos gratuitos en los centros de salud, talleres de prevención y cuidado del cuerpo, testeo rápido de HIV, entrega de preservativos, acompañamiento, orientación, consejería para sus asociados y público en general, etc.

Aunque no figura entre sus prioridades la difusión de la transmisión del virus y de otros temas relacionados, existen algunas ONG que se han involucrado en acciones sobre diversos aspectos de esta temática en la comunidad general y hacia las personas que concurren a sus instalaciones.

A pesar que sólo tres de estas organizaciones participan en alguna red vinculada a VIH-Sida, todas ellas tienen conciencia de la importancia de su rol en la comunidad y muestran interés en realizar algún proyecto/acción sobre HIV-Sida.

En el gráfico 5 se pueden visualizar las principales actividades desarrolladas por las ONG que tienen alguna vinculación con el Programa de VIH-Sida provincial. 


\section{Gráfico 5. Principales acciones realizadas por ONG vinculadas al VIH-Sida Río Gallegos. Año 2019}

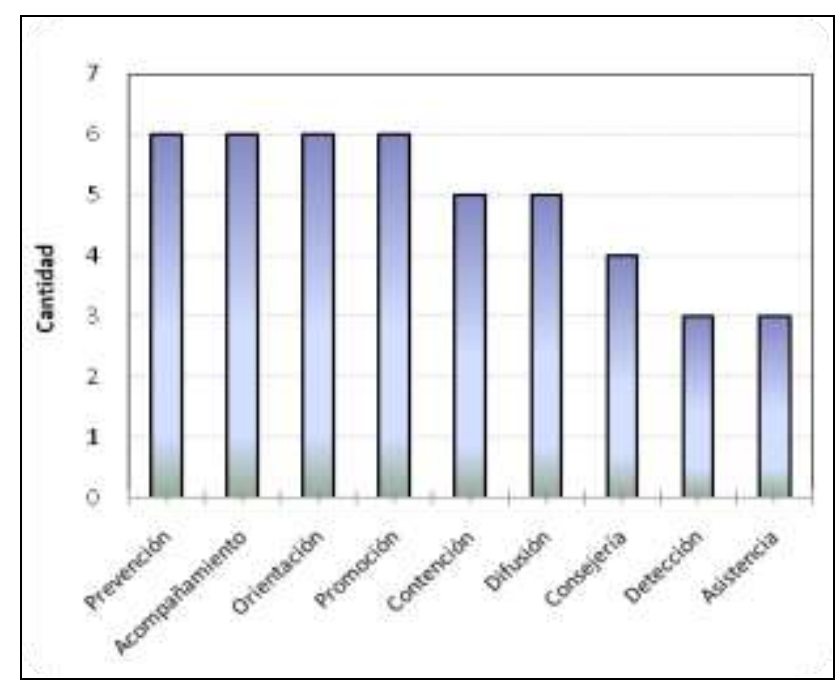

Fuente: Encuesta realizada por Equipo de Investigación. Elaboración propia

Del total de actividades vinculadas al VIH-Sida que las ONG informan, más de la mitad (54\%) corresponden a acciones de tipo social y humanitaria como la prevención y acompañamiento. En menor medida se ubican acciones de tipo médico como la detección, que requieren de equipamiento y de la actuación de profesionales de la salud.

De todos modos, se debe señalar que la mayoría de estas actividades no se llevan a cabo en forma conjunta con el Programa Provincial de HIV-Sida.

En total son siete organizaciones las que sí desarrollan actividades en concordancia con acciones previstas en el Programa. Y otro dato importante es que las personas que actualmente las realizan, han trabajado o han estado relacionadas con el Programa Provincial VIH-Sida.

\section{Información sobre conocimiento del VIH-Sida en la comunidad}

Dentro del contexto y de los objetivos de la presente investigación se considera oportuno y de interés evaluar el conocimiento que tiene la población de Río Gallegos sobre el VIH-Sida y del Programa Provincial.

Con esa finalidad se diseña una encuesta que es aplicada por estudiantes de segundo año de la carrera de Trabajo Social (UARG) en una muestra no aleatoria.

Se realiza un muestreo denominado "de conveniencia" y de tamaño reducido, por lo que los resultados se consideran sólo como información cualitativa a modo de primer sondeo exploratorio sobre el tema.

El análisis de las respuestas obtenidas, indica que las personas tienen información insuficiente: en su mayoría (74\%) desconocen la existencia del Programa Provincial de VIHSida.

El 24\% de personas que dicen conocer dicho Programa, han tomado conocimiento a través de las redes sociales, campañas de análisis de detección gratuitos (tests) y/o medios masivos de comunicación. 
De las respuestas analizadas, puede deducirse que la información que poseen respecto a la enfermedad y al Programa Provincial VIH- Sida es dispar, fragmentada e imprecisa.

Desconocen en su mayoría la existencia del Programa Provincial. Conocen sobre las vías de contagio del virus pero de manera confusa. A modo de ejemplo, 55\% responde que es una enfermedad de transmisión sexual; $37 \%$ que se transmite en las relaciones sexuales sin protección (uso de preservativos).

La mayoría de los entrevistados desconoce que es una enfermedad de atención crónica y además ignoran las características de las sucesivas etapas en la evolución de esta enfermedad $\mathrm{y}$ en su fase terminal.

El conocimiento que manifiestan lo han adquirido por medio de las redes sociales o los medios de comunicación social.

\section{CONCLUSIONES}

El trabajo investigativo realizado y el proceso de análisis que se viene desarrollando, apunta en dos sentidos. Uno, en describir la implementación de las políticas públicas en la atención de las personas que conviven con el virus e identificar los espacios donde se implementa, los programas o proyectos que pueden existir en esta dirección y la relación entre ambas. El segundo objetivo apunta a las necesidades que presentan las personas que conviven con el virus y las estrategias que desarrollan para atender su vida cotidiana en virtud de la atención en el programa provincial. Además de identificar los organismos de salud u organizaciones no gubernamentales que implementan actividades de difusión sobre la temática hacia la comunidad en general y hacia sus asociados y por último si alguno de estas implementa acciones hacia la persona que convive con el virus.

En el análisis se puede afirmar, según los datos reunidos, que la implementación del programa en la ciudad de Rio Gallegos tiene diferentes formas de organización. Primero se ejecuta en referencia directa con lo normado en la Ley $\mathrm{N}^{\circ} 23798$ y su decreto reglamentario 1422 y segundo, la difusión sobre el tema VIH-Sida en la comunidad es escasa para orientarse hacia cambios en las prácticas sociales de mayor integración social de las personas que conviven con el virus.

La atención hacia la persona que convive con el virus se lleva a cabo según lo normado en la Ley $\mathrm{N}^{\circ} 23798$ y su decreto reglamentario $\mathrm{N}^{\circ} 1244$ : detección del virus en sangre, notificación del diagnóstico, acuerdo del tratamiento antirretroviral a implementar en forma conjunta con el médico Infectólogo, la entrega de medicamentos en forma mensual, los controles clínicos pertinentes, resguardo de la información de la persona y aporte de información local para la elaboración de las datos estadísticos a nivel nacional. La forma de atención en este tipo de tratamiento, requiere prácticas sociales para que puedan sostenerse en el tiempo. Pero según el análisis de las entrevistas y de las acciones que se realizan desde el programa para medir la adherencia (controles médicos que realiza la persona o el cumplimiento de las indicaciones del médico Infectólogo, el retiro de la medicación y si se ausenta de estas actividades se recurre a un agente sanitario o trabajador social porque el programa no cuenta con estas especialidades), se podría suponer que es necesario considerar otras formas de prácticas que tengan en cuenta estos aspectos que en la ley no figuran en forma explícita. Una de estas es la organización de los turnos para especialidades médicas o psicológicas, en caso de requerir, dado el impacto del tratamiento antirretroviral que produce en las personas o generar espacios de contención. 
En cuanto a las estrategias que implementan las personas en su vida diaria para la atención y controles médicos de la enfermedad, manifiestan dificultades para conseguir turnos de control, debiendo concurrir en horarios de madrugada para tal fin. Otro inconveniente es la entrega de los medicamentos fuera de término que si bien no siempre ocurre, esto podría repercutir en su tratamiento.

A pesar de que existen estas dificultades, los pacientes no efectúan reclamo alguno, según la información obtenida para este estudio que se considera muy reducida, por lo cual esta situación solo se circunscribe a este caso. Esta dificultad expresada por las personas que se encuentran en tratamiento y que han respondido a la entrevista, no se posicionan como actores con los recursos necesarios para dar a conocer su voz, sino más bien se encuentran en una actitud pasiva. Esto tal vez tiene que ver el impacto que produce en ellos las representaciones sociales y prejuicios que existen sobre una persona portadora de sida. Además buscan como estrategia de contención a las personas que son cercanas y que aceptan su situación de enfermedad. Estos son elementos que si bien se expresa en un contexto reducido, aporta información para comparar con otros estudios sobre el mismo tema.

La difusión de la temática hacia la comunidad para el conocimiento sobre el contagio y controles del virus, es insuficiente porque se detectan que se realizan espacios de trasmisión e intercambio si estos son solicitados por parte de distintas instituciones al programa provincial. Por el conocimiento alcanzado en esta instancia, no se cuenta con un programa o proyecto provincial para la difusión de la temática hacia la comunidad, lo cual crea un vacío en el conocimiento para el cuidado personal y comunitario. En las distintas organizaciones no gubernamentales consultadas tampoco se realizan actividades de difusión, aunque expresan que estarían dispuestos a actividades sobre la temática. Y en las organizaciones que realizan actividades son de testeo rápido, entrega de folletería, entrega de preservativos, etc. La mayoría de estas actividades no están coordinadas con el programa provincial. Estas actividades podrían formar parte de un proyecto de difusión desde el programa.

El conocimiento que las personas de la ciudad tienen sobre el virus se direcciona con las campañas que se realizan y que tienen ver con la forma de trasmisión y su cuidado. También podría pensarse que estos conocimientos son los que fueron difundidos en años anteriores por medio de las campañas nacionales. Este dato refleja la utilidad de la difusión a nivel social para el conocimiento en el cuidado y relación con las personas que están en tratamiento.

En conclusión las formas y modos de atención hacia la personas que conviven con el virus, se implementan según lo normado en la ley por medio del programa nacional y el programa provincial, pero las acciones de difusión en el conocimiento del virus hacia la prevención se encuentra fragmentada y se realizan solo en aquellas organizaciones que sus integrantes están sensibilizados por la temática. Desde el programa provincial y tal vez por el escaso personal que aquí se desempeña, no cuentan con el objetivo de difundir en forma sistemática.

En este sentido la temática a nivel social no tiene en la ciudad de Río Gallegos prioridad a nivel social que apunte a cambios culturales y sociales hacia las personas que conviven con el virus. En concordancia con la perspectiva del presente trabajo no se vislumbrarían prácticas sociales instituyentes, lo cual también repercute en las personas que se encuentran en tratamiento porque se sienten marginadas y el encuentro entre ellas y ellos serían de difícil concreción considerando que no se identifica grupos que tengan como objetivo el reunirse bajo la forma de ayuda mutua u otras posibilidades.

Es importante también pensar sobre lo normado en la ley sobre la no identificación de las personas que se encuentran en tratamiento porque teniendo en cuenta que las problemáticas sociales actuales (violencia de género, casamiento igualitario, entre otras) se han logrado por medio de los reclamos de varios sectores o los mismos protagonistas. 


\section{RECOMENDACIONES}

El trabajo de investigación implementado informa de algunos aspectos de la problemática del VIH-Sida en la ciudad de Río Gallegos. Resta profundizar para un mayor conocimiento, pero no obstante con la información aquí expuesta se pueden proponer algunas acciones.

$\checkmark$ Impulsar un trabajo organizado entre las distintas especialidades médicas, nutricionales, psicológicas y sociales del nosocomio local para un abordaje integral y coordinado de las personas que son atendidas desde el programa provincial.

$\checkmark$ Integrar al equipo interdisciplinario que trabajan con la problemática, la figura del trabajador social de manera estable, así como ampliar el plantel profesional de otras especialidades para contribuir a la adherencia al tratamiento de la persona que convive con el virus, trabajar en la prevención y promover a generar nuevas prácticas sociales más inclusivas.

$\checkmark$ Realizar campañas de difusión a través, de los medios gráficos y televisivos sobre el VIH-SIDA para informar a la población sobre la problemática del VIH-SIDA que tienda a un mayor conocimiento sobre el tema e integrando de manera coordinada a las distintas Ong que realizan un trabajo comunitario.

$\checkmark$ Implementar a nivel social capacitación a referentes de las distintas Ong de la ciudad de Río Gallegos para que puedan replicar en estos espacios el conocimiento adquirido.

$\checkmark$ Propiciar la organización grupos de personas que conviven con el virus de forma voluntaria para la contención tanto de su persona como a sus grupos familiares.

\section{AGRADECIMIENTOS}

Este trabajo se hizo realidad con el acompañamiento de distintas entidades y personas que, con sus aportes y apoyo, lo hicieron posible.

A la Subsecretaría de Salud Comunitaria del Ministerio de Salud Provincial Dra. Bárbara Weinzettel y al personal del Programa Provincial de VIH-Sida, ETS.

Al Dr. Alejandro Gasel por su apoyo y orientación constante.

A Lic. Ana María Cornaglia que nos orienta en el trabajo y análisis estadístico.

A las personas que conviven con el virus que dieron su consentimiento para contar con información desde su punto de vista.

\section{BIBLIOGRAFÍA}

ADELANTADO José, Noguera José A., Rambla Xavier, Sáez Lluís (1998). Las relaciones entre estructura y política sociales: una propuesta teórica: Revista Mexicana de Sociología, Vol. 60, No. 3 (Jul. - Sep.), pp. 123-156. https://doi.org/10.2307/3541320

Dirección de Sida y ETS, Ministerio de Salud de la Nación (2016). VIH y derechos Guía jurídica y de orientación para las personas con VIH en la Argentina. Buenos Aires. https://doi.org/10.35537/10915/5429

Dirección de Sida y ETS, Ministerio de Salud de la Nación. VIH. Boletín sobre el VIH, Sida e ITS en la Argentina. Año XXI. Diciembre de 2018. $\mathrm{N}^{\circ} 35$. https://doi.org/10.35537/10915/60956 
Dirección de Sida y ETS, Ministerio de Salud de la Nación. VIH. Boletín sobre el VIH, Sida e ITS en la Argentina. Año XXI. Diciembre de 2017. N $^{\circ} 34$. https://doi.org/10.35537/10915/60956

GLASER, B. y Strauss A. (1967). The discovery of grounded theory: strategies for qualitative research. New York: Aldine Publishing Company, Capítulo 3: "El muestreo teórico", pp. 45-77. Traducción original Floreal Forni.

HELER, Mario; Casas, Jorge Manuel; Gallego, Fernando Martín (2010). Lógicas de las necesidades: la categoría de "necesidades" en las investigaciones e intervenciones sociales. Espacio editorial. Buenos Aires.

MARGULIES, Susana (2014). Un estudio de antropología de la medicina. 1era. Edición. Editorial de la Facultad de Filosofía y Letras. UBA. CABA. E-book.

MARGULIES, Susana, Barber, Nélida y Recordes, María (2006). VIH-Sida y "Adherencia" al tratamiento. Enfoques y perspectivas. Revista antípoda $\mathrm{N}^{\circ}$ 3. Julio a diciembre. Pág. 281-300. https://doi.org/10.7440/antipoda3.2006.11

Proyecto "Actividades de Apoyo para la Prevención y Control del VIH/Sida en Argentina" (2008.)Estudio nacional sobre la Situación social de las personas viviendo con VIH en la Argentina - 1a ed. - Buenos Aires: Libros del Zorzal. https://doi.org/10.17227/01234870.41folios87.102

SÁNCHEZ VÁZQUEZ, Adolfo (2003). Filosofía de la Praxis. Siglo XXI. México.

SCHLEMENSON, Aldo (1998). Análisis institucional y empresa unipersonal. Paidós. Buenos Aires.

THOMPSON, Andrés (1995). Políticas públicas y sociedad civil en Argentina. El papel de las organizaciones sin fines de lucro. Buenos Aires.

VARA Paiva y otros (2018). Prevención, promoción y cuidado: enfoque de vulnerabilidad y derechos humanos. 1era. Edición. Compilado por José Capriati. CABA.

WAGNER, Alejandra (2006). Actores sociales: los sujetos del cambio Una primera aproximación al análisis de actores. Ficha de cátedra $\mathrm{N}^{\circ} 25$. Cátedra de administración en trabajo social. Facultad de Trabajo Social: Universidad Nacional de la Plata. Buenos Aires. https://doi.org/10.5171/2013.898594

\section{Leyes}

- $\quad \mathrm{N}^{\circ}$ 23798. Ley Nacional de Sida.

- $\quad \mathrm{N}^{\circ}$ 24754. Ley obligatoriedad para las obras sociales.

- $\quad \mathrm{N}^{\circ}$ 25543. Ley Mujer embarazada - test de hiv

- $\quad N^{\circ} 25$ 673. Programa Nacional de Salud Sexual y Procreación Responsable

- $\quad N^{\circ}$ 26150. Programa Nacional de Educación Sexual Integral. 